\title{
FEMALE DRIVERS IN THE UNITED STATES, 1963-2013: FROM A MINORITY TO A MAJORITY?
}

\section{Michael SiVAK}

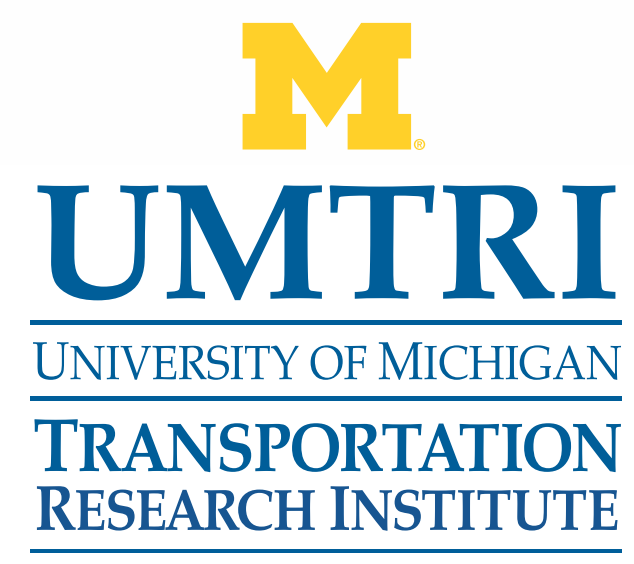


FEMALE DRIVERS IN THE UNITED STATES, 1963-2013:

FROM A MINORITY TO A MAJORITY?

Michael Sivak

The University of Michigan

Transportation Research Institute

Ann Arbor, Michigan 48109-2150

U.S.A.

Report No. UMTRI-2015-16

May 2015 
Technical Report Documentation Page

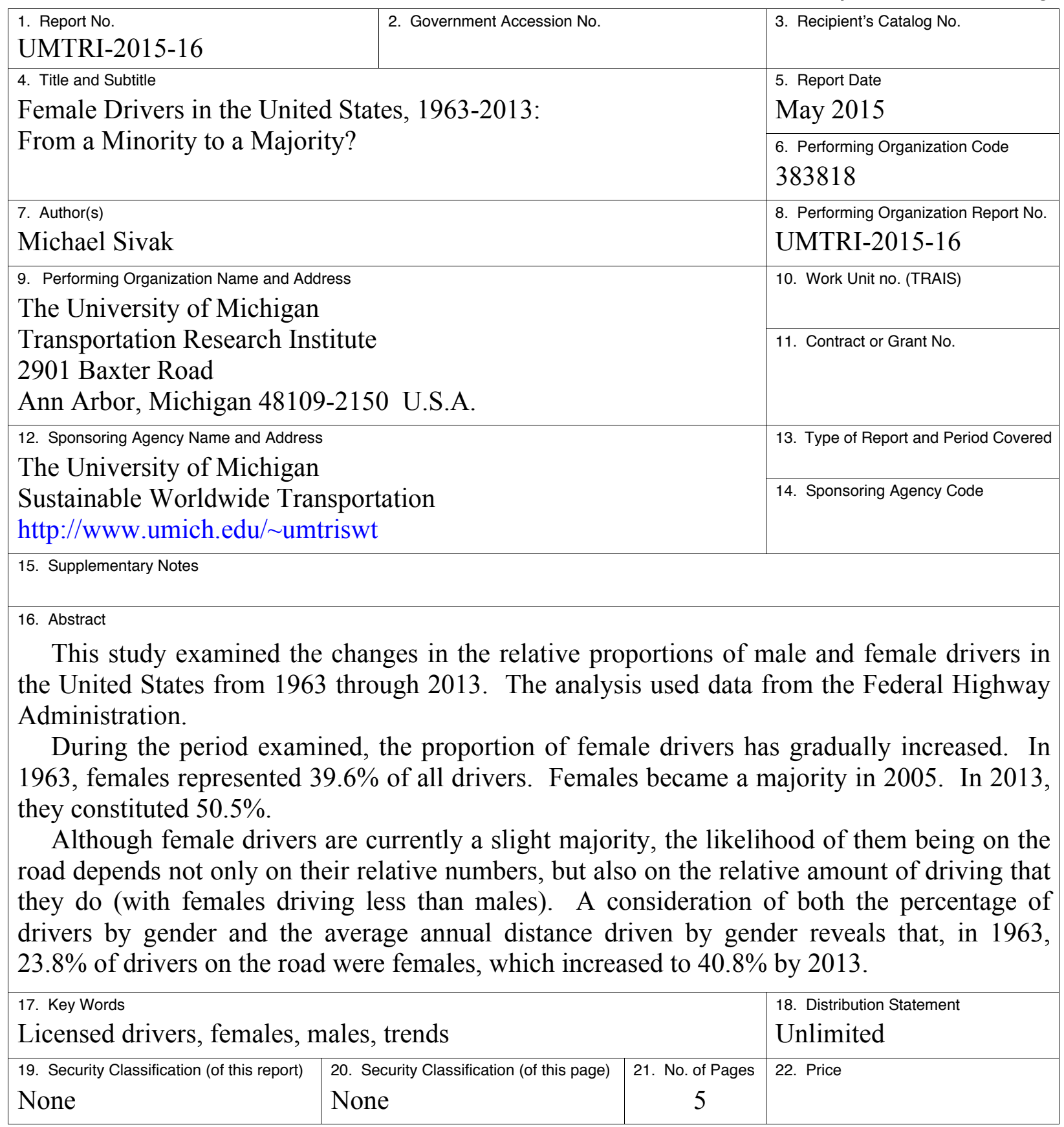




\section{Contents}

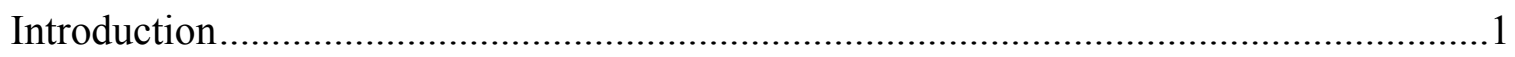

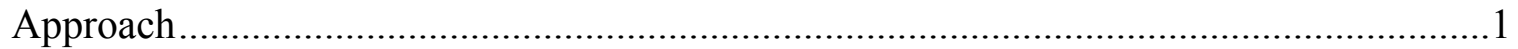

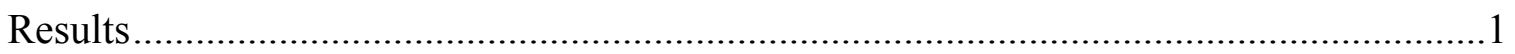

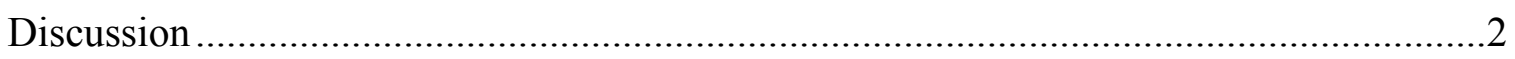

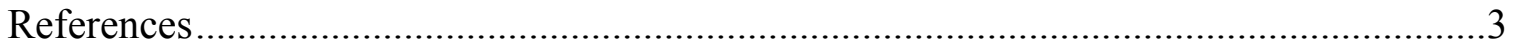




\section{Introduction}

Two years ago, I published a study that examined the changing gender demographics of U.S. drivers from 1963 to 2010 (Sivak, 2013). That study found that, whereas in 1963 females represented only about 40\% of all drivers, by 2010 that percentage increased to just above $50 \%$. However, because females drive less than males, the overall likelihood that a given driver on the road in 2010 was a female was still substantially less than 50\%. The present study extends this analysis through 2013.

\section{Approach}

Annual data on the number of licensed drivers were obtained from the Federal Highway Administration (FHWA, 2015). Data from 1963 through 2013 were examined (the data for the earliest and latest year available, respectively).

\section{Results}

Figure 1 shows female drivers as a percentage of all drivers from 1963 through 2013. In 1963, females constituted $39.6 \%$ of all drivers - the minimum during the examined period. Since 1963, this percentage has gradually increased. The first year in which female drivers became a majority was 2005 . In 2013, females constituted $50.5 \%$ of all drivers - the maximum during the examined period. 


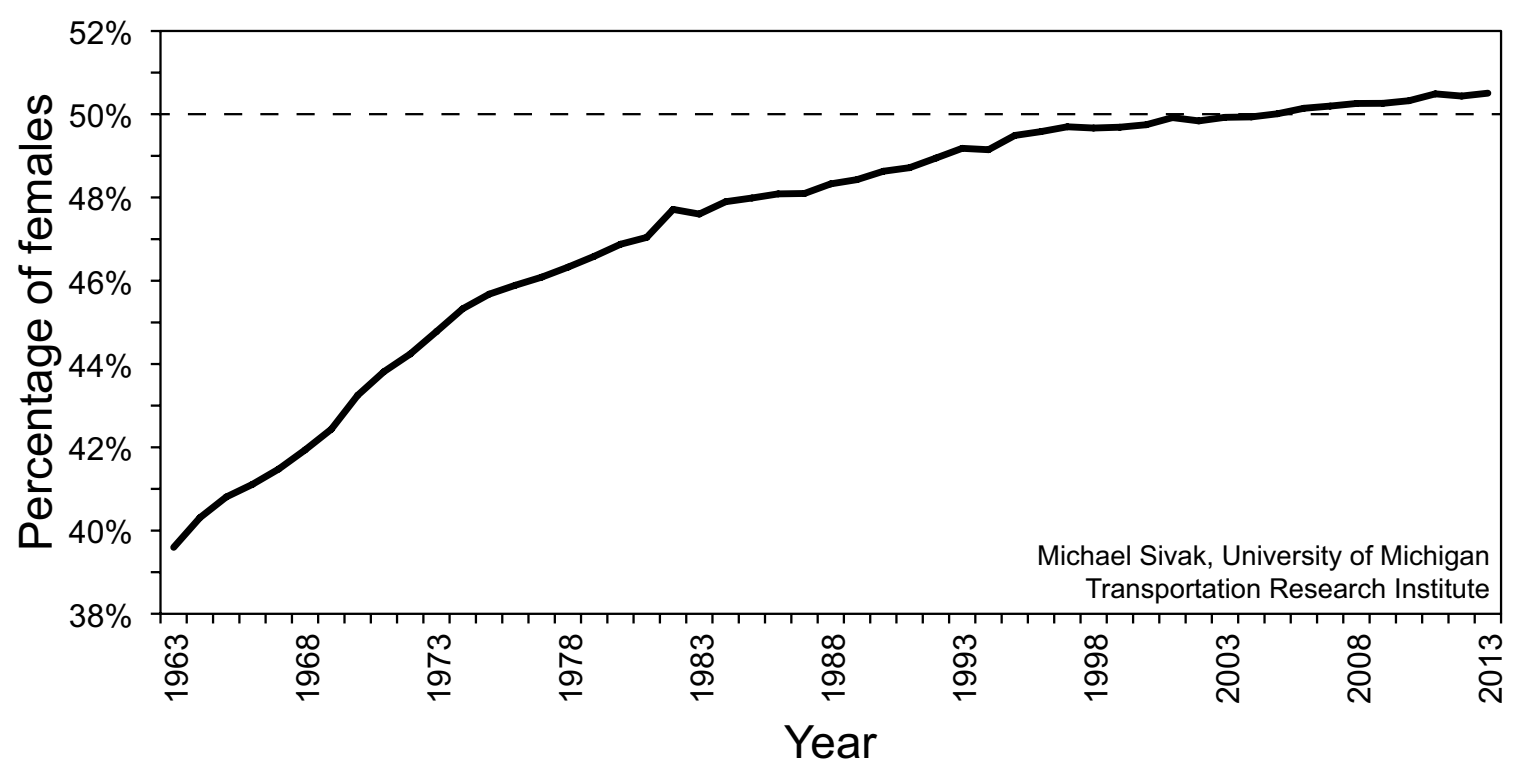

Figure 1. Females with a driver's license as a percentage of all persons with a driver's license, 1963 through 2013.

\section{Discussion}

Although female drivers are currently a slight majority, the likelihood of them being on the road depends not only on their relative numbers, but also on the relative amount of driving that they do. The average annual distances driven by each gender in 1969 and 2009 (the nearest years to 1963 and 2013 with available data) are shown in Table 1. The best estimate is that, from 1963 to 2013, the average distance driven increased by about 33\% for males and $89 \%$ for females. Consequently, while in 1963 the average male drove about 2.1 times the distance of the average female, in 2013 that multiple was down to about 1.5 .

Table 1

Average annual miles driven per licensed driver by gender in 1969 (NPTS, 1973) and 2009 (NHTS, 2011).

\begin{tabular}{|c|c|c|}
\hline Year & Male & Female \\
\hline 1969 & 11,352 & 5,411 \\
\hline 2009 & 15,139 & 10,244 \\
\hline
\end{tabular}


A consideration of both the percentage of drivers by gender and the average annual distance driven by gender reveals that, in 1963, 23.8\% of drivers on the road were females, which increased to $40.8 \%$ by 2013 .

As pointed out in Sivak and Schoettle (2012), the observed gender trends in driver licensing will likely have major implications on the extent and nature of vehicle demand, energy consumption, and road safety. This is the case because, compared to males, females are more likely to purchase smaller, safer, and more-fuel efficient vehicles; females drive less; and females tend to have a lower fatality rate per distance driven.

\section{References}

FHWA [Federal Highway Administration]. (2015). Highway statistics (annual). Available at: http://www.fhwa.dot.gov/policyinformation/statistics.cfm.

NHTS [National Household Travel Survey]. (2011). Summary of travel trends: 2009 National Household Travel Survey. Washington, D.C.: Federal Highway Administration.

NPTS [National Personal Transportation Study]. (1973). Characteristics of licensed drivers. Washington, D.C.: Federal Highway Administration.

Sivak, M. (2013). Female drivers in the United States, 1963-2010: From a minority to a majority? Traffic Injury Prevention, 14, 259-260.

Sivak, M. and Schoettle, B. (2012). The changing gender composition of U.S. drivers. Traffic Injury Prevention, 13, 575-576. 